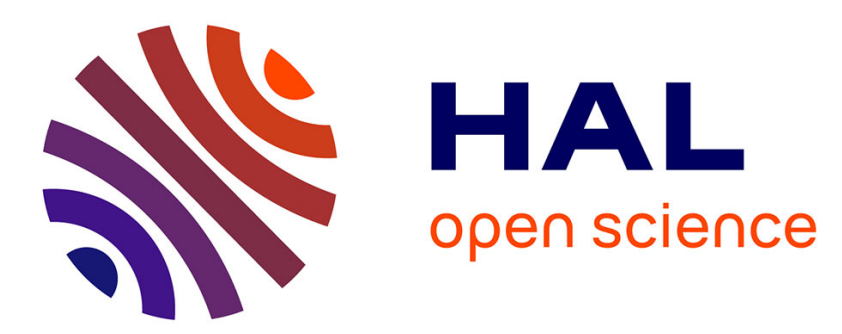

\title{
Assistance tools for generic definition of ITER maintenance tasks and scenarios in advanced supervisory control systems
}

\author{
S. Zieba, F.-X. Russotto, M. da Silva Simoes, Y. Measson
}

\section{- To cite this version:}

S. Zieba, F.-X. Russotto, M. da Silva Simoes, Y. Measson. Assistance tools for generic definition of ITER maintenance tasks and scenarios in advanced supervisory control systems. Fusion Engineering and Design, 2013, 88 (9-10), pp.2067-2072. 10.1016/j.fusengdes.2013.02.088 . cea-01831849

\section{HAL Id: cea-01831849 \\ https://hal-cea.archives-ouvertes.fr/cea-01831849}

Submitted on 7 Jan 2019

HAL is a multi-disciplinary open access archive for the deposit and dissemination of scientific research documents, whether they are published or not. The documents may come from teaching and research institutions in France or abroad, or from public or private research centers.
L'archive ouverte pluridisciplinaire HAL, est destinée au dépôt et à la diffusion de documents scientifiques de niveau recherche, publiés ou non, émanant des établissements d'enseignement et de recherche français ou étrangers, des laboratoires publics ou privés. 


\title{
Assistance tools for generic definition of ITER maintenance tasks and scenarios in advanced supervisory control systems
}

\author{
Stéphane Zieba*, François-Xavier Russotto, Max Da Silva Simoes, Yvan Measson \\ CEA, LIST, Interactive Robotics Laboratory, F-92265 Fontenay-aux-Roses, France
}

\begin{abstract}
This paper concerns the improvement of supervisory control systems in the context of remote handling for the maintenance tasks in ITER. This work aims at providing a single formalism and tools to define in a generic way the ITER maintenance tasks and scenarios for in-vessel and hot cell operations. A threelayered approach is proposed to model these tasks and scenarios. Physical actions are defined for the scene elements. From these physical actions, behaviours are defined to represent high-level functionalities. Finally, interaction modes define the way that behaviours are achieved in terms of human-machine interactions. Case study concerning the blanket maintenance procedure is discussed concerning the contributions of the descriptive model and the context-based assistances to the activities of supervisory control.
\end{abstract}

\section{Introduction}

The work presented in this paper takes place in the EFDA GOT$\mathrm{RH}$ project. This program's aim is to train engineers for activities supporting the ITER project and the long-term fusion programme in European Associations, associates, Fusion for Energy (F4E) and the ITER organization, and Industry. The major objective is to implement a structured Remote Handling (RH) System design and a development-oriented training task that is carried out in a multidisciplinary Systems Engineering framework by using ITER/F4E task and quality assurance processes and available documents, document templates and ITER-relevant software products. The global topic of this project concerns RH maintenance for ITER and works detailed in this paper concern more specifically the advanced functionalities for Supervisory Control Systems.

\footnotetext{
* Corresponding author. Tel.: +330146549198.

E-mail addresses: stephane.zieba@cea.fr (S. Zieba), francois-xavier.russotto@cea.fr (F.-X. Russotto), max.simoes@cea.fr (M. Da Silva Simoes), yvan.measson@cea.fr (Y. Measson).
}

ITER maintenance requires a combination of scheduled and unscheduled replacement tasks both on the machine and in the hot cell during periodic shutdown times and operational periods [1]. Maintained components are to be moved between the Tokamak building and the Hot Cell building through the ports located in the upper, equatorial and divertor regions of the vacuum-vessel (VV). Due to restricted visibility conditions, all these RH tasks require the use of advanced Supervisory Control Systems able to provide operators with efficient virtual reality representation of the environment and context-based assistances, optimizing operations effectiveness, reliability and safety. Complexity and diversity of maintenance tasks require the use of a large set of RH equipment supervised from a control room by human operators organized in work cells. It would be highly inefficient to develop specific supervision systems for each task or equipment. This work thus aims at providing a single formalism and tools to define in a generic way ITER maintenance tasks and scenarios for in-vessel and hot cell operations.

The formalism proposed in this paper is based on three levels defining the actions opportunities available in the environment, the high-level functionalities built on these physical actions and the interactions modes required to achieve these functionalities. This 


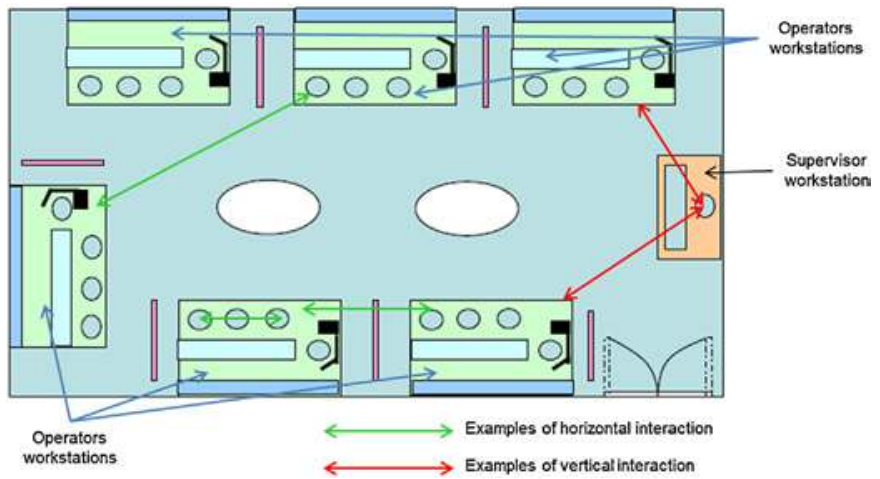

Fig. 1. Interactions in the Remote Handling Control Room. adapted from [1].

three-layered model is used to propose context-based assistances to the operator for heterogeneous robotic tasks.

The remainder of this paper is as follows. The Section 2 details the interactions in the ITER RH control room. The Section 3 presents the descriptive model of the environment based on three levels: actions, behaviours and interaction modes. The Section 4 presents applications of this model through the definition of context-based assistances and an illustrative example for the case of Blanket Remote Handling System.

\section{Interactions in the ITER RH control room}

The ITER RH control room is composed of at least six work cells working in parallel and one supervisor station [1]. Each work cell is composed of four operators supervising the process. Different types of interactions are bound to occur in the $\mathrm{RH}$ control room between people in charge of the process.

Supervision of such complex systems requires different types of interactions depending on the role of the human operator. In the ITER context, the roles of supervisor and operator are identified in the RH control room. The supervisor is in charge of supervising the activity of the control room and coordinating the work cells. The operators are in charge of performing the maintenance tasks with master-slave teleoperation systems.

Cross-scale interactions must be taken into account, that is to say interactions are to be defined between the operators of the same work cell, between the operators and the supervisor and finally between the work cells (Fig. 1). Vertical interactions correspond to the interactions that exist between the supervisor and the operators in the control room. Horizontal interactions correspond to the interactions between operators in the same work cell or between different works cells. These interactions require different forms (written, verbal or computer-supported) and different types of information (joints positions, speed, task progress...) according to the current interaction mode.

The ITER RH operations involve multiple parallel, relatively independent activities carried out by the RH work cells [2]. Maintenance operations in the hot cell can involve different work cells in parallel, working on different equipment and components. A failure in one work cell may thus require shifting from a work cell to another one in order to ensure continuity of the maintenance task. Moreover, the activity of the supervisor station is achieved constantly and in parallel with the activity of the operators' stations.

Shared situation awareness is likely to emerge in the control room via all these interactions. Team processes and communication methods must be implemented to facilitate a shared understanding among the team. A well-known model of situation awareness (SA) is proposed by Endsley [3] and introduces three levels: the perception of information in a finite volume in time and space (SA1), the understanding of their signification (SA2) and the projection of the system state in the future (SA3).

This paper will illustrate later to what extent the model detailed in the next section and the context-based assistances can improve the operator SA.

\section{Three-layered model for the description of ITER maintenance tasks}

\subsection{Definition of the three-layered model}

A three-layered approach is proposed to model the maintenance tasks. This model aims at describing all the potential actions required for the maintenance scenarios in the ITER context (transfer, in-vessel and hot cell operations). The objective is to provide a generic framework in order to avoid the development of specific supervisory control applications for each maintenance task.

The first level of this framework defines the available operations via physical interfaces which are attached to the scene elements. Description of the scene with these interfaces provides a functioncentred model of the environment. Interfaces shall provide physical data to enable actions between elements of the scene according to the operator's needs and to the task requirements (Fig. 2). Interfaces are defined with the following data: type of action, gender of interface and availability in order to check compatibility, position on the object and tolerances to locate the interaction area, approach position and inclusion constraints to enable correct positioning. All these data allow defining precisely the location and the modalities of every potential physical interaction with an object. Interfaces offer learning perspectives for the remote handling system, the operator being able to teach the automated system some new tasks. Such a unified representation for the elements of the scene also facilitates the planning activity for the human operator and its intervening activity by allowing simple modifications of the original action plan.

The second level of the framework is drawn from these physical actions and corresponds to behaviours which are defined to represent high-level functionalities. Behaviours correspond to the logical link between interfaces of two or more objects. They can be initiated provided that there is complementarity between the interfaces. Complementarity is assessed by logical rules on the interfaces data to determine if interaction is possible and to enable the activation of the required behaviour. Learning of the rules which lead to the activation of behaviours is a part of the supervisory control activities for both the human operator and the machine agent.

Initiation, execution and stopping of the behaviours are ruled by the third and last level of the framework in terms of interaction modes. Four interaction modes can be defined based on the modes of autonomy defined in [4]:

- Mode 1: Manual mode.

- Mode 2: Supervised control mode under the authority of the human operator.

- Mode 3: Autonomous control mode under shared authority (the human operator has a limited amount of time to validate or cancel actions proposed by the system before automatic execution).

- Mode 4: Fully autonomous mode without operator intervention.

These modes shall be dynamically adjusted in case of unplanned situations (human errors, technical failures, environmental disturbances). Automatic adjustment of the interaction mode should only be possible in modes 3 and 4 . According to the design of the Operations Management System (OMS), maintenance procedures are hierarchically decomposed into tasks, subtasks, methods and steps [2]. Interaction modes can be set at the level of methods and thus 


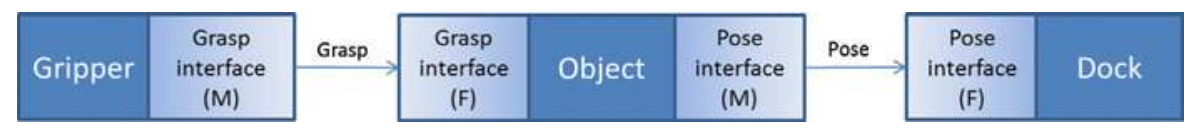

Fig. 2. Definition of interfaces on the scene elements.

define the task allocation between the human operator and the system for each step of the method.

For instance, for the step of the blanket maintenance procedure concerning the flexible support bolts unbolting, the following task allocation can be proposed:

- Mode 1: no action is initiated by the system; the operator is in charge of everything.

- Mode 2: the operator validates every step of the unbolting (by selecting the starting and end poses for the motion and checking correct positions); the motion and the unbolting are achieved automatically by the system.

- Mode 3: the system selects starting and end poses based on the task procedure, then computes and displays possible alternatives for the proposed motion and finally selects one of them; the operator is given a limited amount of time before the automatic execution of these steps.

- Mode 4: the operator only validates the initiation of the procedure; information about progress is displayed.

Table 1 summarizes the contributions offered by the descriptive model and the context-based assistances to the supervisory control application. The objective is to improve the activities in supervisory control as defined by Sheridan: planning, teaching, monitoring, intervening and learning [5]. Some of these contributions concern the improvement of the operator's SA according to the three levels defined by Endsley [3]. Indeed, SA must be guaranteed at all times for the operator, that is to say, the operator must know the actions he has to achieve and the actions that remain under the authority of the machine.

\subsection{Integration of the three-layered model in the ITER RH control system architecture}

The objective of the three-layered model is to propose advanced supervision functionalities that can be applied not only to ITER and the existing modules of the High-Level Control System (HLCS) but also to other domains of application. These functionalities include autonomy and procedure management, context-based assistances and management of human-machine interactions. In the ITER context, the proposed model should mainly interact with two elements of the HLCS: the Supervisor System and the OMS (Fig. 3).

The Supervisor System acts to provide a high level view of the status of work cells and the progression of the tasks [6]. It shall provide features such as the communication with Control, Data Access and Communication system (CODAC), a graphical chart of work cell tasks with clear indications of interactions between work cells and live tracking of the work cells task progress including the possibility to issue high-level commands. The OMS is a system for creating and re-playing procedures written in an unambiguous natural language [6]. It shall provide features such as the management of equipment, tools and components required for tasks and the flexibility to suspend tasks or switch to other tasks.

Cooperation can be initiated between operators in a same work cell or between different work cells (Fig. 1). HMI of the workstation must clearly identify the tasks of each work cell and the planned interactions in the procedure. Dynamic adjustment of the interaction mode and proposal of context-based assistances are ensured by the behaviour and the mode managers. These functionalities aim at being added in the OMS and the Supervisor System. Other blocks of the proposed model have to communicate with HLCS modules such as Virtual Reality Visualization and Computer Assisted Teleoperation so as to display and use context-based assistances and required behaviours.

The next section is devoted to illustrative examples of this model: the definition of context-based assistances and the description of the ITER Blanket module maintenance procedure.

\section{Context-based assistances for RH maintenance tasks and application to the ITER Blanket module maintenance}

\subsection{Context-based assistances for maintenance tasks}

Context-based assistances shall be provided to the operators for different maintenance tasks. Examples of such assistances are being implemented in SCORE, which is the current version of MAGRITTE, a supervisory control application developed at CEA-LIST for several years [7]. This application is based on the communication between Master and Slave controllers of a classical teleoperation system with force feedback and fusion of virtual and real data. SCORE updates MAGRITTE by integrating a real-time physics

Table 1

Contributions and applications of descriptive model and context-based assistances to maintenance tasks.

\begin{tabular}{|c|c|c|c|}
\hline $\begin{array}{l}\text { Activities of } \\
\text { supervisory control }\end{array}$ & Descriptive model & Context-based assistances & Application to maintenance tasks \\
\hline Planning & $\begin{array}{l}\text { Ability to plan heterogeneous robotic } \\
\text { tasks via the common description of } \\
\text { available actions }\end{array}$ & $\begin{array}{l}\text { Improvement of level SA3 } \\
\text { Display projected changes }\end{array}$ & $\begin{array}{l}\text { Determine transitions between work } \\
\text { cells and minimize inactivity time }\end{array}$ \\
\hline Teaching & $\begin{array}{l}\text { Improvement of the model } \\
\text { Add new interfaces dynamically to } \\
\text { increase functionalities }\end{array}$ & $\begin{array}{l}\text { Improvement of level SA2 } \\
\text { Instruct new actions opportunities in } \\
\text { the environment }\end{array}$ & $\begin{array}{l}\text { Definition of operations for equipment, } \\
\text { tools and components }\end{array}$ \\
\hline Monitoring & $\begin{array}{l}\text { Function-centred representation } \\
\text { allows an easy transfer from } \\
\text { descriptive model to implementation } \\
\text { in the environment }\end{array}$ & $\begin{array}{l}\text { Improvement of level SA1 } \\
\text { Reduced workload and time for } \\
\text { situation understanding }\end{array}$ & $\begin{array}{l}\text { Common view for the work cells of the } \\
\text { task progress }\end{array}$ \\
\hline Intervening & $\begin{array}{l}\text { Easy and quick method to define online } \\
\text { modifications of the action plan }\end{array}$ & $\begin{array}{l}\text { Improvement of level SA2 } \\
\text { Reduced workload and time for } \\
\text { decision-making }\end{array}$ & $\begin{array}{l}\text { Adjustment of interaction modes in } \\
\text { case of unexpected event }\end{array}$ \\
\hline Learning & $\begin{array}{l}\text { Predict actions of the system with the } \\
\text { function-centred representation model }\end{array}$ & $\begin{array}{l}\text { Improvement of level SA3 } \\
\text { Learn reasoning of the system }\end{array}$ & $\begin{array}{l}\text { Training of operators with simulation } \\
\text { models }\end{array}$ \\
\hline
\end{tabular}




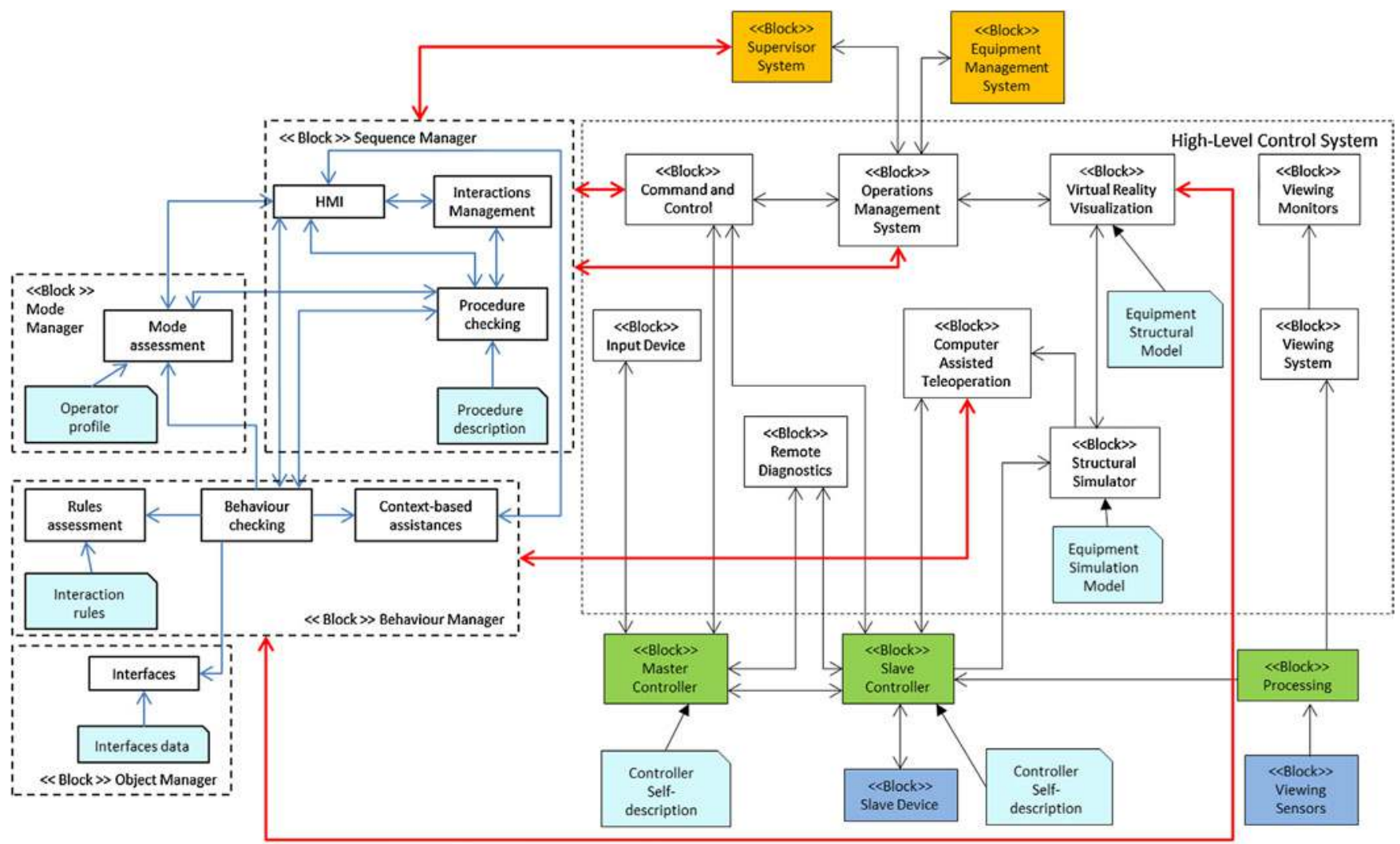

Links between the HLCS module and the proposed architecture

Fig. 3. Integration of the three-layered model in the HLCS architecture.

engine named XDE [8] (developed at CEA) which allows performing accessibility simulation, simulation for operators training and assistances to the operators such as collisions avoidance or haptic virtual guides. SCORE design makes the algorithmic part independent from the visualization part. SCORE can thus be interfaced to different human-machine graphical interfaces such as the Solidworks CAD environment via specific APIs for virtual reality visualization of the scene.

Visual assistances consist in displaying the available actions in the environment. When a procedure step is selected by the operator, the system can display the interfaces which are compatible in the environment. Augmented reality is useful in this case to display relevant information in the field of view of the operator by overlaying the virtual reality visualization for instance. Objective of such assistances is thus to improve the operator's SA by relieving the workload for perception of relevant information in the environment and understanding of this information.

Virtual guides are used to restrain degrees of freedom in order to facilitate the achievement of actions. The objective is to release the operator from the complete control of the motion. Virtual guides are implemented according to two phases: an approach phase and an interaction phase as an example can be seen in the Fig. 4 for an operation of tool clamping. Augmented reality is also relevant for such haptic assistances. Indeed, a transparent representation

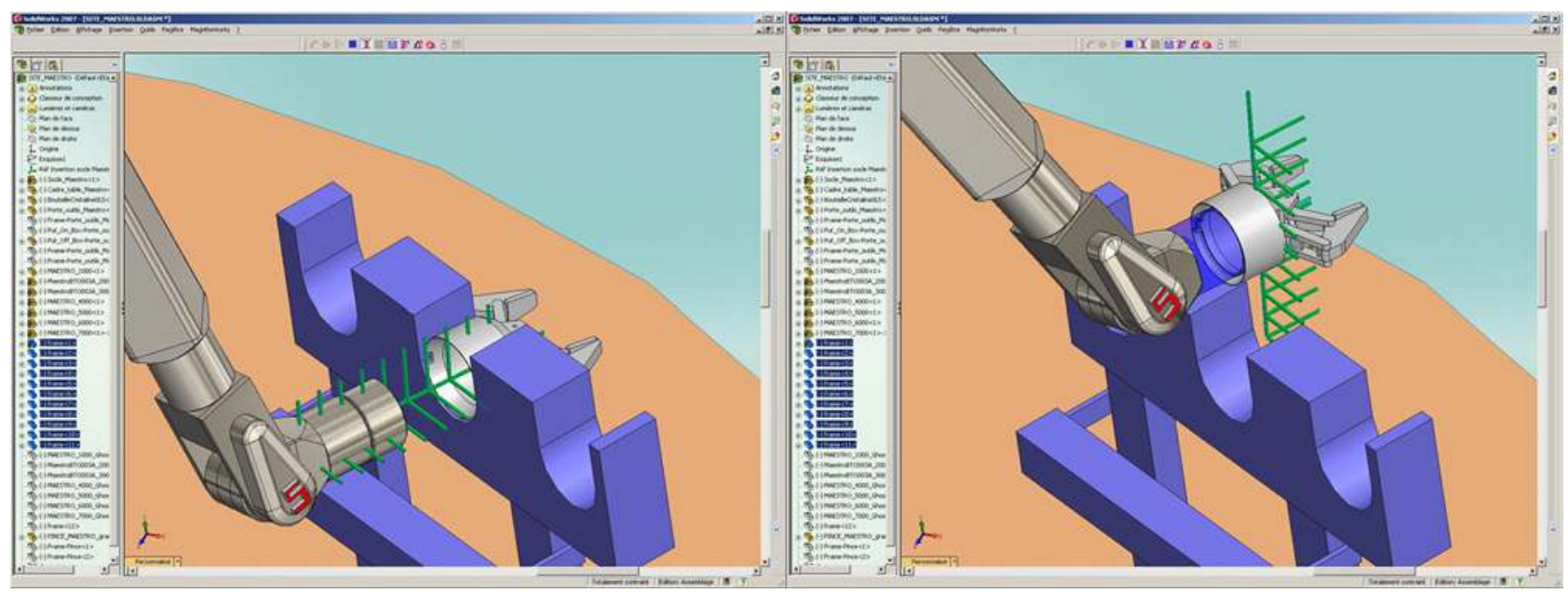

Fig. 4. Illustration of virtual guides for clamping operation. 
Table 2

Application of the three-layered model to Blanket Remote Handling.

\begin{tabular}{|c|c|c|c|c|c|c|c|}
\hline $\mathrm{N}^{\mathrm{o}}$. & Subtask description & Methods & Steps & Interfaces & Behaviours & $\begin{array}{l}\text { Possible interaction } \\
\text { modes }\end{array}$ & $\begin{array}{l}\text { Context-based } \\
\text { assistances }\end{array}$ \\
\hline 3 & $\begin{array}{l}\text { Installation of IVT } \\
\text { inside the VV }\end{array}$ & $\begin{array}{l}\text { IVT system } \\
\text { transport by RH } \\
\text { cask }\end{array}$ & $\begin{array}{l}\text { Load RH cask } \\
\text { Seal RH cask } \\
\text { Move IVT system } \\
\text { from hot cell to VV }\end{array}$ & $\begin{array}{l}\text { Interfaces defined } \\
\text { on cask and port } \\
\text { plugs for sealing } \\
\text { and transfer } \\
\text { operations }\end{array}$ & $\begin{array}{l}\text { Load } \\
\text { Seal } \\
\text { Move }\end{array}$ & $\begin{array}{l}\text { Manual validation of } \\
\text { steps completion and } \\
\text { automatic sealing } \\
\text { and motion } \\
\text { Or } \\
\text { Automatic validation } \\
\text { of each step }\end{array}$ & $\begin{array}{l}\text { Procedure following } \\
\text { Virtual guides for } \\
\text { motion tasks }\end{array}$ \\
\hline 5 & $\begin{array}{l}\text { Blanket module } \\
\text { removal }\end{array}$ & $\begin{array}{l}\text { Flexible support } \\
\text { bolts unbolting }\end{array}$ & $\begin{array}{l}\text { Grasp unbolting } \\
\text { tool } \\
\text { Move to flexible } \\
\text { support bolts } \\
\text { Unbolt flexible } \\
\text { support bolts } \\
\text { Move to RH cask } \\
\text { Release unbolting } \\
\text { tool }\end{array}$ & $\begin{array}{l}\text { Interfaces defined } \\
\text { on tool for grasping } \\
\text { Interfaces defined } \\
\text { on tool and bolts } \\
\text { for bolting } \\
\text { Interface defined } \\
\text { on RH cask and tool } \\
\text { for tool releasing }\end{array}$ & $\begin{array}{l}\text { Grasp } \\
\text { Move } \\
\text { Unbolt } \\
\text { Move } \\
\text { Release }\end{array}$ & $\begin{array}{l}\text { Automatic } \\
\text { achievement of steps } \\
\text { Or } \\
\text { Manual achievement } \\
\text { of steps } \\
\text { Or } \\
\text { Automatic motion } \\
\text { and manual } \\
\text { achievement of other } \\
\text { tasks }\end{array}$ & $\begin{array}{l}\text { Procedure following } \\
\text { Virtual guides } \\
\text { Highlight next action } \\
\text { Highlight relevant } \\
\text { object for bolt } \\
\text { selection }\end{array}$ \\
\hline
\end{tabular}

excerpt adapted from [9].

simulating the object motion that is to be achieved with the virtual guide can be displayed in the virtual reality visualization to help the operator understand the assistance.

\subsection{Application to the ITER Blanket module maintenance procedure}

ITER Blanket maintenance procedure (Fig. 5) is a relevant illustrative example for the application of the proposed formalism. This $\mathrm{RH}$ task is described in [9] and is composed of 13 subtasks. For the purpose of this paper, only parts of two subtasks - the installation of in-vessel transporter (IVT) inside the VV and the blanket module removal - are detailed (Table 2 ). They give an overview of different tasks that can be defined using the three-layered model and the context-based assistances.

Blanket remote handling requires a combination of sequential and parallel activities, the supervisor station being in charge of coordinating these different tasks. Coordinated motions of the rail deploying equipment and the vehicle manipulator are required during the rail deployment procedure. Monitoring of the rail deformation can be achieved in parallel with the maintenance operations such as bolting and cutting in order to prevent any deviation from correct position. This coordination shall be monitored by 2 different work cells or by 2 operators within the same work cell, which could avoid latencies in communication.

Communication and coordination between the work cells must be provided in order to ensure natural transitions between the tasks. The supervisory control system must be able to provide to

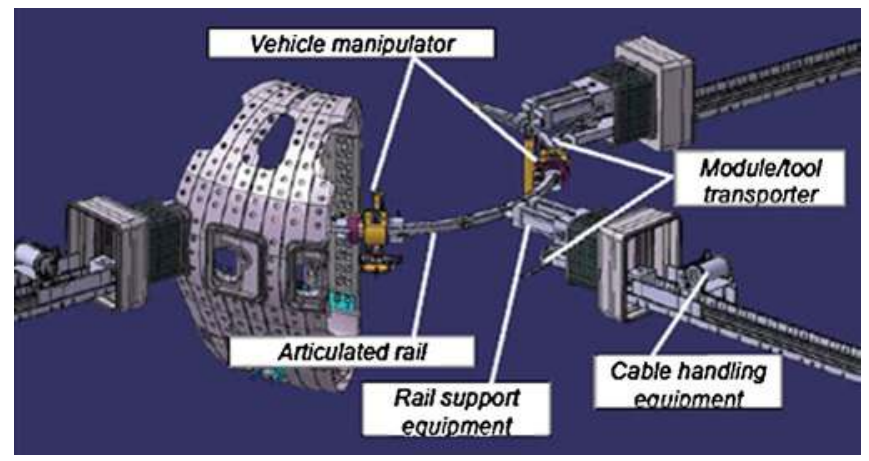

Fig. 5. Blanket Remote Handling System.

Credit: ITER Organization. http://www.iter.org. the operators the most relevant actions which are available in the environment according to the required point of view; that is to say, operator on a specific task or supervisor of the global process. This part of coordination process is directly linked with the OMS functionalities, which can be augmented by taking into consideration dynamic adjustment of interaction modes according to the context.

\section{Conclusion and perspectives}

A three-layered model is proposed in this paper to describe tasks of remote handling maintenance in a generic way allowing the definition of context-based assistances. Future works on the proposed model will focus on a more complete definition of the interaction modes for the task allocation between the human operator and the system. Proposals made in this paper will have to be assessed via an experimental campaign which will compare remote handling tasks without and with assistances for performance criteria such as completion time, collisions, accuracy or number of errors in the procedure.

Perspectives concerning advanced assistances shall be related to the development of an intention recognition module. The objective of intention recognition is to relieve the operator mental workload, that is to say the factors that are to be expanded to perform the required task, by computing the next actions to be performed based on situation analysis. Relevance of this intention recognition module regarding the operator workload shall be assessed by subjective and performance-based techniques. Perspectives also concern collaborative work that is to be carried out in the context of the EFDA GOT RH programme. Theoretical and applied exchanges centred on the concept of haptic shared control [10] shall take place in the continuity of the project. Merging intention recognition and haptic shared control is likely to offer perspectives in terms of assistances which shall contribute to the improvement of effectiveness and reliability of maintenance operations in ITER and other application domains.

\section{Acknowledgments}

This work was carried out under the EFDA Goal Oriented Training Programme (WP10-GOT-GOTRH) and financial support of CEA, which are greatly acknowledged. The views and opinions expressed herein do not necessarily reflect those of the European Commission. 


\section{References}

[1] ITER Remote Handling High-Level Control System White Paper, ITER_D_2UUN6T v1.0, August 8th 2009.

[2] Handbook, Annex B - High-Level Control System Specification, ITER_D_4GTJJP v1.1, November 22nd 2011.

[3] M.R. Endsley, Automation and situation awareness, in: R. Parasuraman, M. Mouloua (Eds.), Automation and Human Performance: Theory and Applications, Lawrence Erlbaum, Mahwah, NJ, 1996, pp. $163-181$.

[4] S. Zieba, P. Polet, F. Vanderhaegen, Using adjustable autonomy and human-machine cooperation for the resilience of a human-machine system - application to a ground robotic system, Information Sciences 181 (2011) 379-397.
[5] T.B. Sheridan, Human supervisory control, in: A.P. Sage, W.B. Rouse (Eds.), Handbook of Systems Engineering and Management, John Wiley \& Sons, New York, USA, 1999, pp 591-628.

[6] System Requirement Document(SRD) for PBS 23-07 - Remote Handling Control System, ITER_D_2DRWQ6, v3.1, November 10th 2009.

[7] C. Leroux, M. Guerrand, C. Leroy, Y. Measson, B. Boukarri, MAGRITTE: a graphic supervisor for remote handling interventions, in: Proceedings of ASTRA'04, 8th ESA Workshop on Advanced Space Technologies for Robotics and Automation, Noordwijk, Netherlands, 2004.

[8] X. Merlhiot, J.L. Garrec, G. Saupin, C. Andriot, The xde physics simulation kernel, in: 2nd Joint Conference on Multibody System Dynamics, 2012.

[9] Design Description Document: Remote Handling Equipment, Chapter 3: Blanket Remote Handling Equipment, N 23 DDD 65 01-07-06 R0.2, July 2004.

[10] D.A. Abbink, M. Mulder, E.R. Boer, Haptic shared control: smoothly shifting control authority? Cognition, Technology and Work 14 (March (1)) (2012) 19-28. 